\title{
Protection with thymoquinone against formaldehyde-induced neurotoxicity in the rats
}

\author{
Saygin $\mathrm{B}^{1}$, Esrefoglu $\mathrm{M}^{2}$, Bayindir $\mathrm{N}^{2}$, Tok $\mathrm{OE}^{2}$, Selek $\mathrm{S}^{3}$, Bulut $\mathrm{H}^{3}$, Ozer OF${ }^{3}$, Ozturk $\mathrm{A}^{4}$, \\ Yilmaz $\mathrm{O}^{4}$, Meydan $\mathrm{S}^{5}$ \\ Bezmialem Vakıf University, Medical Faculty, Department of Anatomy, Istanbul,Turkey. \\ smeydan@bezmialem.edu.tr
}

\begin{abstract}
INTRODUCTION: This study aimed to investigate the neurotoxic damage of formaldehyde (FA), which is commonly used in medicine and industrial fields, for the hippocampus of rats and the protective role of thymoquinone (TQ) against this neurotoxicity.

METHODS: There were five groups with eight rats in each. Two control groups were formed, in one of them physiological saline was applied and in the other one corn oil was applied. FA was injected in Group 3. Group 4 was exposed to FA and TQ simultaneously. Group 5 received TQ only. At the end of the experiment animals were sacrificed and brain tissues were removed for biochemical and histopathological investigation.

RESULTS: Catalase (CAT), glutathione peroxidase (GSH-px) and superoxide dismutase (SOD), all known as enzymes with antioxidant activities, were increased in FA and TQ simultaneously administered group. FA caused prominent subarachnoidal hemorrhage and vacuolization. Vacuolization was not observed but occasional subarachnoidal hemorrhage was detected in the FA+TQ group.

CONCLUSION: Neurotoxic damage in hippocampus induced by FA was reverted by administration of TQ (Tab.

1, Fig. 1, Ref. 26). Text in PDF www.elis.sk.

KEY WORDS: formaldehyde, hippocampus, neurotoxic damage, thymoquinone.
\end{abstract}

\section{Introduction}

Hippocampus, a division of the limbic system, is related with emotions, memory and learning. It participates in integration and storage of recently learned data and transporting experiences from short term memory to long term memory (1).

Formaldehyde is a form of aldehyde compound and is both an indoor and outdoor air pollutant (2). Especially anatomists, histologists and medical students who take the course of cadaver dissection are often exposed to influence of FA. Besides, FA is included in tobacco smoke and smoke produced from photochemical reactions and burning of general combustibles (3). Growing evidences revealed that elongated exposure to FA causes chemical accumulation (4-6).

There are is a wide range of evidence indicating memory damage as a result of prolonged FA exposure. Formaldehyde accumulation results in a decrease in hippocampal neurons $(7,8)$

${ }^{1}$ Bezmialem Vakıf University, Medical Faculty, Istanbul,Turkey, ${ }^{2}$ Bezmialem Vakıf University, Medical Faculty, Department of Histology, Istanbul,Turkey, ${ }^{3}$ Bezmialem Vakıf University, Medical Faculty, Department of Biochemistry, Istanbul,Turkey, ${ }^{4}$ Bezmialem Vakıf University, Medical Faculty, Department of Psychiatry, Istanbul,Turkey, and ${ }^{5}$ Bezmialem Vakıf University, Medical Faculty, Department of Anatomy, Istanbul,Turkey

Address for correspondence: S Meydan, Bezmialem Vakıf University, Medical Faculty, Department of Anatomy, 34093, Istanbul,Turkey. and impairment of memory (9). Epidemiologic studies show that exogenous FA exposure causes cognitive regression and is related with neurofilament changes and demyelinisation in hippocampal neurons in humans (10-12).

Decreases in activities of the prominent antioxidant enzymes Superoxide dismutase (SOD), catalese (CAT) and glutathion peroxidase (GSH-px), are used for demonstrating cellular damage related with oxidative stress (13).

Nigella Sativa (N.Sativa, Black Cumin) is a herbal medicine with a large history. According to literature, N.Sativa's biologic activity is predominantly related with its fatty components, especially with TQ (14). TQ has been reported to scavenge several species of reactive oxygen radicals including superoxide radicals and hydroxyl radicals (15). Besides, TQ was reported to be used as a protective agent against neurotoxic damage (16). However, to the best of our knowledge, a study concerning the protective effect of TQ against neurotoxic damage caused by FA on hippocampus, has not been performed yet. Thus, we decided to demonstrate the characteristics of neurotoxic damage caused by FA on hippocampus and find out whether TQ has a protective effect on this damage or not.

\section{Material and methods}

Animals and applications

A total of 40 male rats (Wibstar Albino) were used for the current study. Rats were divided into five groups, with eight rats in 
each. Temperature was set to $22 \pm 2{ }^{\circ} \mathrm{C}$. The light was arranged in the form of 12 hours for each,daytime and nighttime. The rats from the first control group (Group 1) were injected with physiological saline solution intraperitoneally. Rats in group 2 were administered $1 \mathrm{ml}$ of corn oil via gavage. Rats in group 3 were injected FA via intraperitoneal route with a dose of $10 \mathrm{mg} / \mathrm{kg}$ diluted in $10 \%$ physiological saline solution. Rats in group 4 were injected FA at the same dose and duration as in the third group and additionally were administered $20 \mathrm{mg} / \mathrm{kg}$ TQ in $1 \mathrm{ml}$ corn oil via gavage. Rats in group 5 were administered $20 \mathrm{mg} / \mathrm{kg}$ TQ with $1 \mathrm{ml}$ corn oil via gavage.

Fifteen days later the animals were sacrificed and brain tissues were removed for biochemical and histopathological examinations. One hemisphere of each rat was fixated in $10 \%$ formaldehyde for light microscope examinations. Hippocampus region of the other hemisphere was removed for biochemical examination, placed into glass bottles, labeled, and stored frozen for the eventual determination of SOD, GSH-Px and CAT activities.

\section{Biochemical analyses}

The tissues were weighed and homogenized in ice-cold Tris$\mathrm{HCl}$ buffer $(50 \mathrm{mM}, \mathrm{pH} 7.4)$. All procedures were performed at $+4{ }^{\circ} \mathrm{C}$. Tissue homogenates were centrifuged to remove debris, and the clear supernatant fluids were separated and kept at $-80^{\circ} \mathrm{C}$ until the enzyme activity measurements were performed (about a week later).

\section{Determination of SOD activity}

The method to determine SOD activity for current study is based on recording the optic density (OD) of blue formasane produced while Nitro blue tetrazolium (N.B.T) and superoxide radicals generated using xantine and xantine oxidase (XOD) react at $560 \mathrm{~nm}$ wavelength. SOD inhibits formasane reaction by disposing superoxyde radicals. Inhibition rate depends on SOD activity in the environment. SOD activity is expressed as $\mathrm{U} / \mathrm{g} \mathrm{Hb}$ and $\mathrm{U} / \mathrm{g}$ protein in blood and tissue, respectively. The process is briefly as follows: erythrocyde hemolysate or tissue homogenate is diluted with phosphate buffer. A buffer solution composed of 25 $\mu \mathrm{l}$ of diluted hemolysate or tissue homogenate, $50 \mathrm{mmol} / \mathrm{L}$ CAPS (3-[siklohexylaminol]-1-propanesulfonic acid) and $0.094 \mathrm{mmol} / \mathrm{L}$ EDTA (pH 10.2) and $850 \mu 1$ substrate solution composed of 0.05 $\mathrm{mmol} / \mathrm{L}$ xantine sodium and $0.025 \mathrm{mmol} / \mathrm{L}$ 2-(4-iodophenyl)-3-(4nitrophenol)-5-phenyltetrasolium chloride (INT) are mixed. $125 \mu 1$ xantine oxidase $(80 \mathrm{U} / \mathrm{ml})$ is added to the mixture and accelerance of absorbance is recorded at $505 \mathrm{~nm}$ for 3 minutes (17).

\section{Determination of GSH-Px activity}

Glutathione (GSH), reduced in the presence of $\mathrm{H} 2 \mathrm{O} 2$, is oxidised by GSH-Px and becomes oxidised glutathione (GSSG). GSSG converts back to GSH through glutathione reductase activity. The cofactor for this reaction is reduced nicotinamide adenine dinucleotide phosphate (NADPH). Amount of NADPH used is screened as the reduction of absorbance at $340 \mathrm{~nm}$ wavelength. GSH-Px activity is expressed as $\mathrm{U} / \mathrm{g} \mathrm{Hb}$ and $\mathrm{U} / \mathrm{g}$ protein in blood and tissue,respectively. The process is briefly as follows: $980 \mu \mathrm{l}$ mixture composed of $1 \mathrm{mmol} / \mathrm{L}$ Na2EDTA, $2 \mathrm{mmol} / \mathrm{L}$ reducted gluthione, $0.2 \mathrm{mmol} / \mathrm{L} \mathrm{NADPH}, 4 \mathrm{mmol} / \mathrm{L}$ sodium azide and 1000 $\mathrm{U}$ glutathione reductase buffered in $50 \mathrm{mmol} / \mathrm{L}$ TRIS and $20 \mu \mathrm{l}$ eriythrocyde hemoliysate or tissue homogenate is mixed and incubated for 5 minutes at $37^{\circ} \mathrm{C}$. Reaction is started by adding 8.8 $\mathrm{mmol} / \mathrm{L}$ hydrogen peroxide and reductions in absorbance are recorded for 3 minutes (18)

\section{Determination of CAT activity}

The method is described by Aebi. At $25{ }^{\circ} \mathrm{C}$ in erythrocyde hemolysate or tissue homogenate, decomposition rate of the substrate $\mathrm{H} 2 \mathrm{O} 2$ is tracked spectrophotometrically at $240 \mathrm{~nm}$ for 30 seconds. Activity is expressed as $\mathrm{U} / \mathrm{g} \mathrm{Hb}$ and $\mathrm{U} / \mathrm{g}$ protein in blood and tissue, respectively (19).

\section{Histological examination}

For histopathological analysis, brain tissues were fixed in 10 $\%$ neutral buffered formaldehyde and embeded in paraffin. $5 \mu \mathrm{m}$ thick sections obtained from paraffin blocks were stained with hematoxylin-eosin (H-E). Samples were examined and scored by a blind observer using a Nikon Eclipse i5 light microscope with a Nikon DS-Filc camera and the Nikon NIS Elements version 4.0 image analysis systems (Nikon Instruments Inc., Tokyo, Japan).

\section{Statistical analysis}

SPSS 20 package programme was used. ANOVA test was applied and $\mathrm{p}<0.05$ was considered as significant. All numerical results was expressed as mean $\pm \mathrm{SD}$.

\section{Results}

The weight gain in FA group was much less than the weight gain in control group. The weight gain in treatment group was found to be less than that of the control group and higher than that of the FA group.

\section{Biochemical results}

The mean CAT, GSH-Px and SOD enzyme activities were decreased in formaldehyde administered rats compared to control group ( $\mathrm{p}<0.001)$ (Tab. 1). Additionally, the mean CAT, GSH-Px

Tab. 1. CAT, SOD and GSH-Px values of the hippocampal tissue samples of the groups $(n=8)$.

\begin{tabular}{lccc}
\hline Group & $\begin{array}{c}\text { CAT } \\
(\mathrm{U} / \mathrm{g})\end{array}$ & $\begin{array}{c}\text { SOD } \\
(\mathrm{U} / \mathrm{g})\end{array}$ & $\begin{array}{c}\text { GSH-Px } \\
(\mathrm{U} / \mathrm{g})\end{array}$ \\
\hline I - Control & $41.6 \pm 2.9$ & $4.2 \pm 0.5$ & $43.4 \pm 1.3$ \\
(Physiological saline solution) & $34.4 \pm 5.8$ & $3.3 \pm 0.2$ & $48.4 \pm 2.0$ \\
II - Control (Corn Oil) & $25.5 \pm 0.9$ & $2.7 \pm 0.2$ & $26.7 \pm 2.9$ \\
III - Formaldehyde & $41.2 \pm 4.3$ & $4.0 \pm 0.4$ & $55.1 \pm 3.0$ \\
IV - Formaldehyde + & $40.9 \pm 4.4$ & $3.4 \pm 0.3$ & $37.1 \pm 1.3$ \\
Thymoquinone & $<0.001$ & $<0.001$ & $<0.001$ \\
V - Thymoquinone & $<0.001$ & $<0.001$ & $<0.001$ \\
\hline $\mathrm{p}<$ (I-III) & $\mathrm{p}<$ (III-IV) &
\end{tabular}

Values are expressed as mean \pm standard error. $n$ - number of subjects; CAT - catalase; SOD - superoxide dismutase; GSH-Px - glutathione peroxidase 

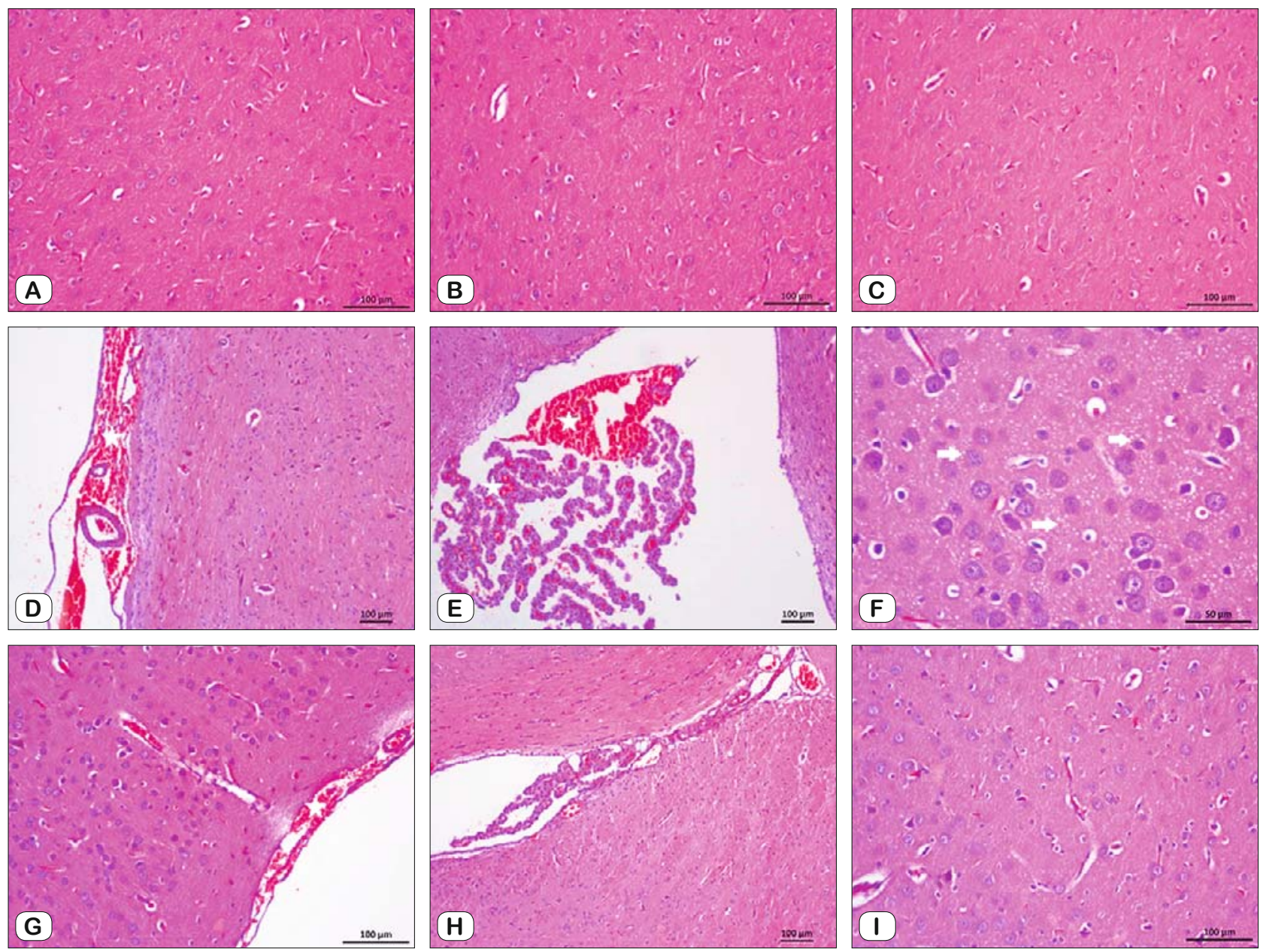

Fig. 1. A. Brain histology is normal in physiologic saline group. H-E; 20 X. B. Brain histology is normal in corn oil group. H-E;20 X. C. Brain histology is normal in thymoquinone group. $\mathrm{H}-\mathrm{E} ; 20 \mathrm{X}$. D. Brain section of formaldehyde group (White star: subarachnoid hemorrhage) $\mathrm{H}-\mathrm{E}$; $10 \mathrm{X}$. E. Brain section of formaldehyde group (White star: subarachnoid hemorrhage) H-E; $10 \mathrm{X}$. Brain section of formaldehyde group (White arrow: vacuolisation) H-E; 40 X. G. Treatment group (White star: subarachnoidal hemorrhage) H-F; 20 X. H. Treatment group; no hemorrhage is seen. $\mathrm{H}-\mathrm{E} ; 10 \mathrm{X}$. I. Treatment group. No vacuolisation is seen. $\mathrm{H}-\mathrm{E} ; 20 \mathrm{X}$

and SOD enzyme activities were increased in FA and TQ administered rats compared to FA administered rats $(\mathrm{p}<0.001)$ (Tab. 1).

\section{Light microscopic results}

Histopathological results are shown in Figure 1. Histological features of the brains of the rats from the control and TQ groups were normal in apperances (Fig. $1 \mathrm{~A}-\mathrm{C}$ ). Intracellular vacuolization, intracerebral hemorrhage, and subarachnoidal hemorrhage were detected in the rats from FA group (Fig. 1D-F). In the FA+ TQ group vacuolization or hemorrhage were not detected, while partial subarachnoidal hemorrhage was observed (Fig. 1G-I).

\section{Discussion}

The results obtained from biochemical and histological examination revealed neurotoxic and destructive effects of FA on hippocampus region. According to the results, TQ was able to prevent the mentioned damage.
SOD, CAT and GSH-px are the enzymatic antioxidant systems of the cells. In a trial aimed to determine the toxic effect of FA on hippocampus, FA was detected to cause oxidative stress, to be neurotoxic and to decrease the levels of antioxidant enzymes SOD and GSH-Px (20). In another study, SOD and GSH-px activities in prefrontal tissue samples of rats which were applied FA injection were found to be significantly lower compared to control group. Therefore, FA was pointed out to cause neuronal toxicity (21). Excess doses of FA application for 30 days significantly reduced hippocampal activity and demonstrated diminishment of NMDA receptor activity, besides, hippocampal FA accumulation was reported in the process of diseases which impair memory, like senile dementia (22). Research concerning accumulation of FA in visceral tissues other then brain was also carried out. Methanol was administered to rats, and in the light of the preliminary information that methanol is metabolised in liver and transformed to FA, antioxidant enzyme systems in liver tissues of rats were assessed. Enzymatic antioxidant systems like SOD, CAT and 
GSH-Px and nonenzymatic antioxidant systems were found to be impaired (23). We found out that FA triggered reductions in antioxidant enzyme levels of hippocampal tissues, which was similar with previous studies. In this view, we suggest that FA causes neurotoxicity in hippocampus via oxidative damage.

TQ is a potent antioxidant according to many recent studies. In a study performed in 2017, SOD and CAT enzyme activities were reduced after administration of lipopolysaccharides (LPS), followed by an increase after TQ administration. Moreover, LPS were shown to enhance the production of proinflammatory cytokines like IL-1, IL-6 and TNF by activating neuroinflammatory reactions in hippocampus and potentially contributing to neuronal dysfunction, causing impairment of memory and learning. Subsequently, these harmful effects were reverted by administration of TQ (24). In a different trial of brain ischemia, SOD and CAT activities and GSH levels were increased after giving oral TQ. It was supposed that TQ reverted the damage after brain ischemia, possibly by reducing the oxidative stress (25). Likewise, in our study, TQ was shown to increase SOD, CAT and GSH-Px activity and revert the neurotoxicity caused by FA on hippocampus.

Intraventricular injection of FA was shown to impair memory and learning, besides, caused apoptosis and lipid peroxidation in hippocampal neurons in a recent study (26). In one study basophilic dark stained picnotic nuclei of hippocampal neurons have been detected after experimental FA toxicity (20). In a further study, apoptotic cells were observed in prefrontal cortices of animals exposed to FA. FA was then reported to be the agent causing damage fn these tissues (21). As mentioned above, FA triggers neuronal toxicity throughout the whole brain tissue by several effects. We also found vacuolisation and subarachnoid and intracerebral hemorrhage in brain tissues of rats exposed to FA. When TQ was applied along with FA, no intracerebral hemorrhage and vacuolisation and less subarachnoid hemorrhage was detected. Thus, we may suggest that TQ has a protective effect on brain tissue.

\section{Conclusion}

The results of current experimental study indicate that FA causes neurotoxic damage in rats' hippocampal tissues and TQ reverts these damages. Moreover, the effects of TQ are accompanied with an increase in antioxidant enzyme activities and a decrease in oxidative damage biomarker levels.

The key eligibility of our study is that to the best of our knowledge, it is the first study to research protective effect of TQ against toxic effects of FA on tissues. Also, we demonstrated tissue damage caused by FA and healing provided by TQ both with histologic examination and changes in antioxidant enzyme activities.

The most clear limitation of our study is that FA was administered via intraperitoneal route. Due to the fact that FA has a marked hepatic first pass metabolism, FA activity may have been diminished in our study. Other remarkable deficiency is that we did not examine memory and learning functions of rats, which are useful for evaluation hippocampal functions.
We suggest that further research focused on antioxidant systems and behavioral systems including testing memory and learning functions may reinforce the favourable effects of TQ against tissue damage.

\section{References}

1. Lieberwirth C, Pan Y, Liu Y, Zhang Z, Wang Z. Hippocampal adult neurogenesis: Its regulation and potential role in spatial learning and memory. Brain Res 2016; 1644: 127-140.

2. Songur A, Ozen OA, Sarsilmaz M. The toxic effects of formaldehyde on the nervous system. Rev Environ Contam Toxicol 2010; 203: 105-118.

3. Triebig G, Zober MA. Indoor air pollution by smoke constituent - a survey. Prev Med 1984; 13 (6): 570-581.

4. Main DM, Hogan TJ. Health effects of low-level exposure to formaldehyde. J Occup Med 1983; 25 (12): 896-900.

5. Sorg BA, Tschirgi ML, Swindell S, Chen L, Fang J. Repeated formaldehyde effects in an animal model for multiple chemical sensitivity. Ann N Y Acad Sci 2001; 933 (1): 57-67.

6. Li Y, Song Z, Ding Y et al. Effects of formaldehyde exposure on anxiety-like and depression-like behavior, cognition, central levels of glucocorticoid receptor and tyrosine hydroxylase in mice. Chemosphere 2016; 144: 2004-2012.

7. Cui X. Inhaled formaldehyde on the effects of GSH level and distribution of formaldehyde. China J Prev Med 1996; 3: 186.

8. Gurel A, Coskun O, Armutcu F, Kanter M, Ozen OA. Vitamin E against oxidative damage caused by formaldehyde in frontal cortex and hippocampus: biochemical and histological studies. J Chem Neuroanat 2005; 29 (3): 173-178.

9. Malek FA, Möritz KU, Fanghänel J. A study on the effect of inhalative formaldehyde exposure on water labyrinth test performance in rats. Ann Anat 2003; 185(3): 277-285.

10. Kilburn KH. Neurobehavioral impairment and seizures from formaldehyde. Arch Environ Health 1994; 49 (1): 37-44.

11. Kilburn KH, Warshaw R, Thornton JC. Formaldehyde impairs memory, equilibrium, and dexterity in histology technicians: effects which persist for days after exposure. Arch Environ Health 1987; 42 (2): $117-20$.

12. Perna RB, Bordini EJ, Deinzer-Lifrak M. A case of claimed persistent neuropsychological sequelae of chronic formaldehyde exposure: clinical, psychometric, and functional findings. Arch Clin Neuropsychol 2001; 16 (1): 33-44.

13. Singh BK, Sharma SR, Singh B. Antioxidant enzymes in cabbage: variability and inheritance of superoxide dismutase, peroxidase and catalase. Sci Hortic 2010; 124 (1): 9-13.

14. Woo CC, Kumar AP, Sethi G, Tan KH. Thymoquinone: potential cure for inflammatory disorders and cancer. Biochem Pharmacol 2012; 83 (4): 443-451.

15. Badary OA, Taha RA, Gamal el-Din AM, Abdel-Wahab MH. Thymoquinone is a potent superoxide anion scavenger. Drug Chem Toxicol 2003; 26 (2): 87-98.

16. Gülşen İ, Ak H, Çölçimen $\mathbf{N}$ et al. Neuroprotective effects of thymoquinone on the hippocampus in a rat model of traumatic brain injury. World Neurosurg 2016; 86: 243-249. 


\section{$726-730$}

17. Sun Y, Oberley LW, Li Y. A simple method for clinical assay of superoxide dismutase. Clin Chem 1988; 34 (3): 497-500.

18. Barlow-Walden LR, Reiter RJ, Abe $M$ et al. Melatonin stimulates brain glutathione peroxidase activity. Neurochem Int 1995; 26 (5): $497-$ 502.

19. Cohen G, Dembiec D, Marcus J. Measurement of catalase activity in tissue extracts. Neurochem Int 1970; 34 (1): 30-38.

20. Ozmen E, Ozsoy SY, Donmez N, Ozsoy B, Yumuşak N. The protective effect of $\mathrm{L}$-carnitine against hippocampal damage due to experimental formaldehyde intoxication in rats. Biotech Histochem 2014; 89 (5): 336-341.

21. Zararsiz I, Kus I, Ogeturk M et al. Melatonin prevents formaldehyde-induced neurotoxicity in prefrontal cortex of rats: an immunohistochemical and biochemical study. Cell Biochem Funct 2007; 25 (4): 413-418.

22. Tong Z, Han C, Luo W et al. Accumulated hippocampal formaldehyde induces age-dependent memory decline. Age (Dordr) 2013; 35 (3): 583-596.
23. Skrzydlewska E, Farbiszewski R. Decreased antioxidant defense mechanisms in rat liver after methanol intoxication. Free Radic Res 1997; 27 (4): 369-375.

24. Bargi R, Asgharzadeh F, Beheshti F, Hosseini M, Sadeghnia HR, Khazaei M. The effects of thymoquinone on hippocampal cytokine level, brain oxidative stress status and memory deficits induced by lipopolysaccharide in rats. Cytokine 2017; 96: 173-184.

25. Al-Majed AA, Al-Omar FA, Nagi MN. Neuroprotective effects of thymoquinone against transient forebrain ischemia in the rat hippocampus. Eur J Pharmacol 2006; 543: 40-47.

26. Tang XQ, Zhuang YY, Zhang P et al. Formaldehyde impairs learning and memory involving the disturbance of hydrogen sulfide generation in the hippocampus of rats. J Mol Neurosci 2013; 49 (1): 140-149.

Received July 6, 2018. Accepted August 23, 2018. 